\title{
ESTUDO DA ACESSIBILIDADE EM AMBIENTES DE LAZER NA CIDADE DO NATAL/RN
}

\author{
Recebido em: 10/09/2009 \\ Aceito em: 03/05/2010 \\ Francisco Ricardo Lins Vieira de Melo ${ }^{1}$ \\ Débora Luciana dos Santos Brandão ${ }^{2}$ \\ Laise Chaves de Oliveira ${ }^{2}$ \\ Larissa Raquel Klemig e Silva ${ }^{2}$ \\ Lorenna Marques de Melo Santiago ${ }^{2}$ \\ Renata Nóbrega Delgado ${ }^{2}$ \\ Universidade Federal do Rio Grande do Norte - UFRN \\ Natal - RN - Brasil
}

RESUMO: As discussões sobre a inclusão social das pessoas com deficiência física na sociedade apontam para a importância de ambientes acessíveis que lhes permitam exercitar o direito de acesso aos diferentes espaços sociais. Diante disso, objetivou-se verificar a acessibilidade de alguns espaços de lazer na cidade do Natal/RN. O estudo descritivo foi realizado em ambientes de lazer - praias, parques, cinemas e teatros - que foram avaliados através de um roteiro composto de 14 itens que consistem em estruturas físicas de acesso aos espaços. Observou-se que os cinemas foram os que possuíam melhores condições de acesso seguido dos parques. Concluiu-se que os ambientes de lazer avaliados necessitam de melhorias para permitir que as pessoas com deficiência física ou mobilidade reduzida exerçam sua cidadania nos espaços de lazer.

PALAVRAS-CHAVE: Atividades de Lazer. Pessoas com Deficiência. Estruturas de Acesso.

\section{STUDY OF ACCESSIBILITY IN ENVIRONMENTS OF LEISURE IN NATAL / RN CITY}

ABSTRACT: The discussion about the social inclusion of the people with physical disabilities in the society shows the importance of accessible places to permit them

\footnotetext{
${ }^{1}$ Doutor em Educação, Universidade Federal do Rio Grande do Norte, Departamento de Fisioterapia/ Programa de Pós-Graduação em Educação.

${ }^{2}$ Graduandas em Fisioterapia, Universidade Federal do Rio Grande do Norte. 
Francisco R. L. V. de Melo, Débora L. dos S.

Estudo da Acessibilidade em Ambientes de Lazer ...

Brandão, Laise C. de Oliveira, Larissa R. K. e Silva,

Lorenna M. de M. Santiago e Renata N. Delgado

exercising their right of access to different social places. Ahead of this, the objective was to verify the accessibility of some leisure places in Natal/RN city. The descriptive observational study was carried out in leisure places - beaches, parks, cinemas and theaters - which were evaluated through a guide composed by 14 items that consist of physical structures of access to the places. We observed that the cinemas showed better conditions of access followed by the parks. Concluded that the leisure places evaluated need improvements to permit the people with physical deficiency or reduced mobility exert their citizenship in the leisure spaces.

KEYWORDS: Leisure Activities. Disabled Persons. Architectural Acessibility.

\section{INTRODUÇÃO}

O conceito de lazer é amplo, variado e vem se modificando através dos tempos. Porém, diante da diversidade de variáveis existentes em seu abrangente contexto, bem como, da subjetividade expressa por vários autores em suas particularidades para descrevê-lo, torna-se um tanto complexo determinar com precisão a conceituação do lazer.

Apesar disso, pode-se afirmar que a esse, podem ser acrescidos os conceitos de qualidade de vida, saúde e cidadania, já que o lazer, em sua forma ideal, auxilia no rompimento da alienação do trabalho, promove a integração do ser humano no contexto social, assim como, o desenvolvimento da sua capacidade crítica, criativa e transformadora, além de proporcionar condições de bem-estar físico e mental do ser humano (MESSA et al, 2005).

De acordo com Marcellino (1996), a "especificidade concreta" do lazer, considerada em sua manifestação na sociedade, é colocada como reivindicação social. Portanto, seu significado volta-se para a questão da cidadania, da participação cultural.

Em síntese, a consideração da "especificidade concreta" do lazer leva em conta o seu entendimento amplo em termos de conteúdo, as atividades que envolve, os valores que propicia, a consideração dos seus aspectos educativos, as suas possibilidades 
Francisco R. L. V. de Melo, Débora L. dos S. $\quad$ Estudo da Acessibilidade em Ambientes de Lazer ... Brandão, Laise C. de Oliveira, Larissa R. K. e Silva,

Lorenna M. de M. Santiago e Renata N. Delgado

enquanto instrumento de mobilização e participação cultural, e as barreiras socioculturais verificadas para seu efetivo exercício, tanto intraclasses como interclasses sociais (PELLEGRIN, 1996).

Pelo fato do espaço do lazer ser caracterizado como espaço de encontro e de convívio, ele possui uma grande importância social, devendo ser palco para a integração e inclusão de todas as camadas e grupos da sociedade. Estes espaços devem, portanto, ser alvo de políticas públicas estruturantes, evitando a segregação e exclusão de pessoas com limitações funcionais.

Já em 1977, o arquiteto Le Corbusier ${ }^{3}$ levantou possíveis soluções urbanísticas para a questão do lazer, que envolviam esferas da vida humana e os problemas urbanos como o transporte, as áreas verdes, a distribuição da população, os desequilíbrios ecológicos e, inclusive, a necessidade de adaptação das áreas em questão (apud PELLEGRIN, 1996).

Quando se fala do entorno que envolve a pessoa com deficiência, percebe-se que seu convívio se mantém limitado à família, clínica e escola. Isso ocorre numa tentativa, às vezes frustrante, de alcançar a normalidade, na qual as atividades voltam-se mais especificamente para as carências apresentadas. Com isso, os aspectos que dizem respeito ao lazer, comumente são obstruídos por atividades ligadas ao tratamento e reabilitação deixando, muitas vezes, de evidenciar o potencial existente, restringindo a pessoa com deficiência de momentos lúdicos fora do ambiente comum a sua rotina e, como consequiência, limitando a vivência de experiências capazes de contribuir para a sua corporeidade (ROCHA et al, 2001).

\footnotetext{
${ }^{3}$ LE CORBUSIER. Por uma Arquitetura. São Paulo: Perspectiva, 1977.
} 
Francisco R. L. V. de Melo, Débora L. dos S.

Estudo da Acessibilidade em Ambientes de Lazer ...

Brandão, Laise C. de Oliveira, Larissa R. K. e Silva,

Lorenna M. de M. Santiago e Renata N. Delgado

Aliada a outras formas de exclusão social, as pessoas com deficiência enfrentam a falta de acessibilidade a muitos espaços ditos "públicos", a falta de conhecimento a respeito de questões relacionadas a seus direitos, o superprotecionismo por parte da família e das pessoas que cercam esses indivíduos e a falta de políticas públicas de lazer ou o despreparo quando são desenvolvidas. (MAIA; ALMEIDA, 2008).

Marcelino (1996) ainda observa que mesmo com a obtenção de recursos financeiros para a promoção de mudanças nos setores públicos, ainda ocorre, em algumas regiões, a má utilização dos mesmos, devido a ausência de parâmetros norteadores da ação.

Mesmo diante desse contexto, a importância do lazer permeia diversas discussões a nível mundial, e diante disso, alguns documentos reafirmam os pensamentos gerados em torno do lazer.

Dentre eles, está a Carta Internacional de Educação para o Lazer, elaborada e aprovada no Seminário Internacional da Associação Mundial de Recreação e Lazer World Leisure and Recreation Association (WLRA), em Jerusalém-Israel, no período de 2 a 4 de agosto de 1993 e ratificada pelo conselho da WLRA em Jaipur na Índia, em dezembro de 1993.

A referida carta informa aos governos, às organizações não governamentais e às instituições de ensino a respeito do significado e dos benefícios do lazer e da educação para e pelo lazer. O lazer é considerado pela Carta Internacional um direito humano básico, assim como educação, trabalho e saúde, e ninguém deverá ser privado desse direito por discriminação de sexo, idade, raça, religião, saúde, deficiência física ou situação econômica. No item acessibilidade, o ensino de lazer na comunidade deve “trabalhar com grupos comunitários existentes para minimizar as barreiras e otimizar o 
Francisco R. L. V. de Melo, Débora L. dos S.

Estudo da Acessibilidade em Ambientes de Lazer ...

Brandão, Laise C. de Oliveira, Larissa R. K. e Silva,

Lorenna M. de M. Santiago e Renata N. Delgado

acesso a serviços de lazer". A Carta ainda sugere a eliminação das barreiras, impedimentos e injustiças através de programas de intervenção direta, indireta, de fomento e de suporte.

Com base nesta mesma perspectiva, foi aprovada por aclamação, na cidade de Salamanca, Espanha, no dia 10 de junho de 1994, a Conferência Mundial sobre Necessidades Educativas Especiais: Acesso e Qualidade, conhecida como Declaração de Salamanca, na sua linha de ação, contempla o lazer das Pessoas com Deficiência no Item II, Diretrizes de Ação no Plano Nacional, Art. 17, sugerindo aos países que “devem ser adotadas medidas legislativas paralelas e complementares em saúde, lazer, formação profissional e trabalho".

Não apenas no contexto mundial, mas também no Brasil, Leis e documentos asseguram à pessoa com deficiência o direito ao lazer buscando propiciar seu bem estar pessoal e social. Segundo o Art. $2^{\circ}$ da Lei $n^{\circ} 7.853$, de 24 de outubro de 1989:

Ao Poder Público e seus órgãos cabe assegurar às pessoas com deficiência o pleno exercício de seus direitos básicos, inclusive dos direitos à educação, à saúde, ao trabalho, ao lazer, à previdência social, ao amparo à infância e à maternidade, e de outros que, decorrentes da Constituição e das leis, propiciem seu bem-estar pessoal, social e econômico.

A legislação também deixa claro o direito ao acesso da pessoa com deficiência aos meios de comunicação social; incentiva a prática desportiva formal e não formal como direito de cada um e o lazer como forma de promoção social; promove a inclusão de atividades desportivas para pessoa com deficiência na prática da educação física ministrada nas instituições de ensino públicas e privadas; apóia e promove a publicação e o uso de guias de turismo com informação adequada à pessoa com deficiência; e estimula a ampliação do turismo à pessoa com deficiência ou com mobilidade reduzida, mediante a oferta de instalações hoteleiras acessíveis e de serviços adaptados de 
Francisco R. L. V. de Melo, Débora L. dos S.

Estudo da Acessibilidade em Ambientes de Lazer ...

Brandão, Laise C. de Oliveira, Larissa R. K. e Silva,

Lorenna M. de M. Santiago e Renata N. Delgado

transporte. Para obtenção desses objetivos, os órgãos e as entidades da Administração

Pública Federal direta e indireta, promotores ou financiadores de atividades desportivas e de lazer, concorrem técnica e financeiramente.

As discussões a luz da inclusão social da pessoa com deficiência na sociedade atual, especificamente daquela com deficiência física, apontam para a importância de ambientes acessíveis para que estas pessoas possam exercer o seu direito de ir e vir, nos diferentes espaços sociais, inclusive os de lazer. Essa problemática se torna ainda mais relevante quando se estima para os países em vias de desenvolvimento de 12 a $15 \%$ da população apresentando alguma deficiência. O censo demográfico de 2000 do Instituto Brasileiro de Geografia e Estatística (IBGE) estimou que dentre os 169.872.856 brasileiros, aproximadamente $14,5 \%$ da população possuem algum tipo de deficiência, destes, cerca de 38,03\% possuem deficiência física. Estima-se que na cidade de Natal/RN há uma superação da média nacional, apresentando $17 \%$ de pessoas com deficiência.

Diante da premissa de que o lazer é uma atividade necessária ao desenvolvimento bio-psíquico-social do homem e sua prática é influenciada, sobretudo, pelo Estado, na medida em que este pode implementar políticas públicas para o setor, além de oferecer espaços físicos necessários e adequados para a sua execução, o presente estudo objetivou verificar se a estrutura do ambiente de alguns espaços de lazer da cidade do Natal/RN encontra- se acessível para receber as pessoas com deficiência física, considerando, principalmente os espaços de lazer disponibilizados à população da cidade.

\section{MATERIAIS E MÉTODOS}


Francisco R. L. V. de Melo, Débora L. dos S.

Estudo da Acessibilidade em Ambientes de Lazer ...

Brandão, Laise C. de Oliveira, Larissa R. K. e Silva,

Lorenna M. de M. Santiago e Renata N. Delgado

Trata-se de um estudo observacional descritivo, realizado na cidade de Natal/RN, no período de abril a maio de 2008.

De início foram selecionados as praias, os parques, os cinemas e os teatros como sendo os espaços de lazer que seriam avaliados. Essa escolha ocorreu pelo fato de estes serem os ambientes de lazer mais freqüentados pela população da cidade.

Uma vez definindo esses ambientes, as avaliações foram feitas por meio de visitas a onze locais, os quais foram: três praias (Praia de Ponta Negra, Praia do Meio e Praia da Redinha); dois parques (Parque das Dunas e Parque das Mangueiras); dois cinemas (Cinemark e Moviecom); e quatro teatros (Teatro Alberto Maranhão, Teatro Municipal Sandoval Wanderley, Casa da Ribeira e Teatro de Cultura Popular).

Foi utilizada uma ficha de avaliação contendo 14 itens: pisos, área de circulação, rampas, corrimãos, portas, elevadores, corredores, estacionamento, rebaixamento de calçada para travessia de pedestres, telefones públicos, bilheterias, sanitários, espaços físicos reservados em teatros e cinemas e sinalização de degraus. Tais itens foram observados de acordo com a Associação Brasileira de Normas Técnicas (ABNT, 2004) pela norma NBR 9050/94 de Acessibilidade a Edificação, Mobiliário, Espaços e Equipamentos Urbanos, através da qual nos foi possível classificar cada item como “adaptado" ou "não-adaptado".

O recurso empregado para as mensurações dos itens quanto ao comprimento, a altura e a largura foi uma fita métrica de metal auto-retrátil. Além disso, utilizou-se o auxílio de uma câmera fotográfica, sem contar com a ficha de avaliação para os espaços físicos de lazer de Natal/RN, já referida. 
Francisco R. L. V. de Melo, Débora L. dos S.

Estudo da Acessibilidade em Ambientes de Lazer ...

Brandão, Laise C. de Oliveira, Larissa R. K. e Silva,

Lorenna M. de M. Santiago e Renata N. Delgado

A pesquisa da qual se originou esse artigo buscou mensurar, portanto, o quanto os espaços de lazer na cidade de Natal estão adequados para o acesso das pessoas com deficiência física.

Foi realizada uma análise descritiva através de freqüência percentual das variáveis analisadas e os resultados obtidos nesse estudo estão demonstrados na forma de gráficos.

\section{RESULTADOS E DISCUSSÕES}

Considerando a avaliação das praias GRAF. 1, os resultados de adequação para a área de circulação indicou $100 \%$ de adequação para pessoas com deficiência física. Quando se refere a pisos, estes se encontram em uma porcentagem de 66,7\% de adequação. As rampas, estacionamento e o rebaixamento de calçada para travessia corresponderam a 33,3\% de adequação. Corrimãos, telefones públicos, sanitários e sinalização de degraus não estão adequados de acordo com a norma.

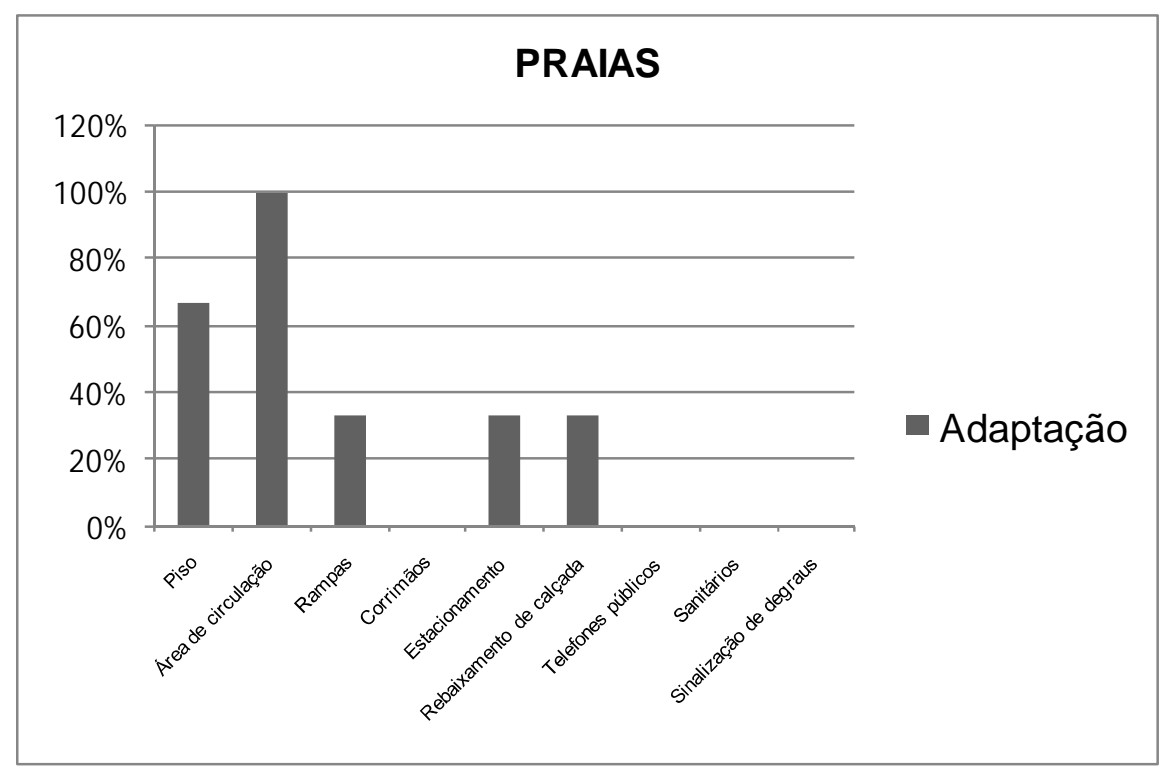

GRAFICO 1 - Avaliação das condições de acessibilidade das praias, Natal/2008. 
Francisco R. L. V. de Melo, Débora L. dos S.

Brandão, Laise C. de Oliveira, Larissa R. K. e Silva,

Lorenna M. de M. Santiago e Renata N. Delgado
Estudo da Acessibilidade em Ambientes de Lazer ...

Os parques analisados GRAF. 2, apresentavam os itens área de circulação, pisos, rampas e rebaixamento de calçada para travessia com $100 \%$ de adequação para a acessibilidade das pessoas com deficiência física. O estacionamento, os corrimãos, as portas e a sinalização de degraus em $50 \%$ e os telefones públicos e sanitários não atingiram os níveis de adequação.

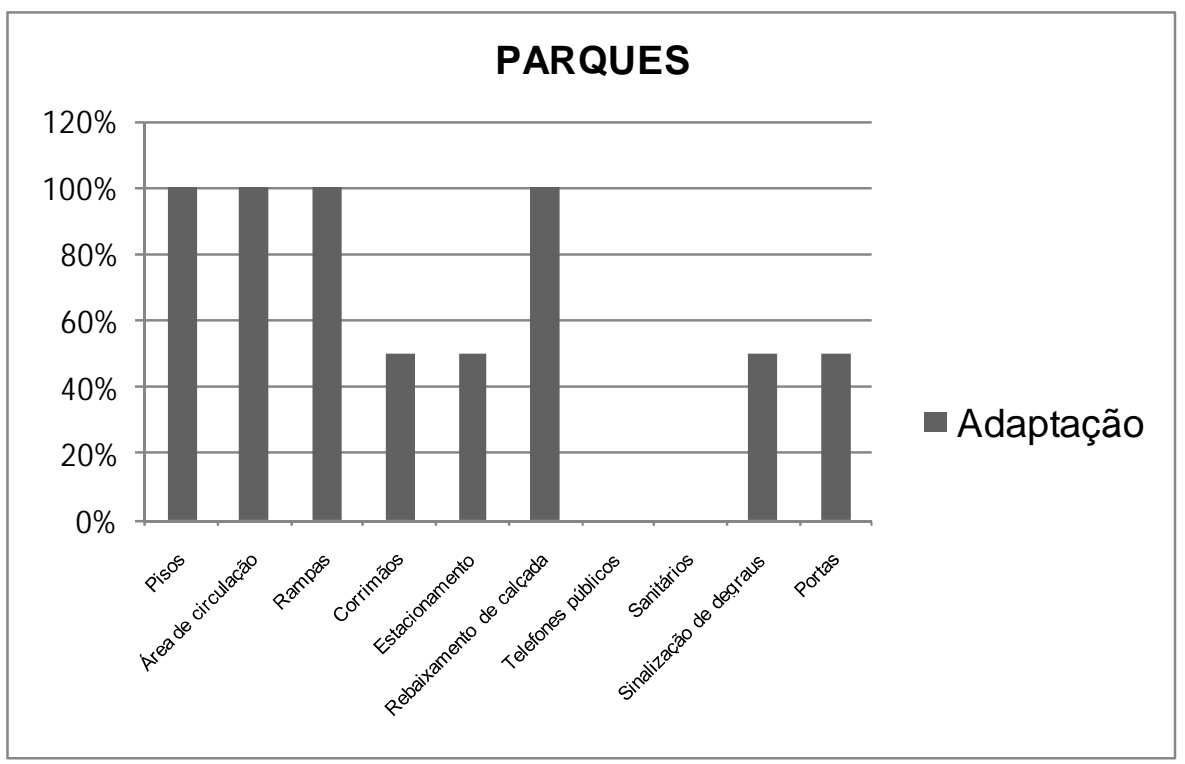

GRAFICO 2 - Avaliação das condições de acessibilidade dos parques, Natal/2008.

Os teatros analisados GRAF. 3 apresentam áreas de circulação, pisos e portas com $100 \%$ de adequação, enquanto os corrimãos e as rampas encontravam-se adaptados em $75 \%$, os corredores e o rebaixamento de calçadas para travessia em $50 \%$, os telefones públicos, a bilheteria, os sanitários, os espaços físicos reservados para pessoas com deficiência em teatros e cinemas e a sinalização de degraus apresentavam $25 \%$ de 
Francisco R. L. V. de Melo, Débora L. dos S.

Estudo da Acessibilidade em Ambientes de Lazer ...

Brandão, Laise C. de Oliveira, Larissa R. K. e Silva,

Lorenna M. de M. Santiago e Renata N. Delgado

adequação, já os elevadores e o estacionamento não se encontravam em níveis de adequação.

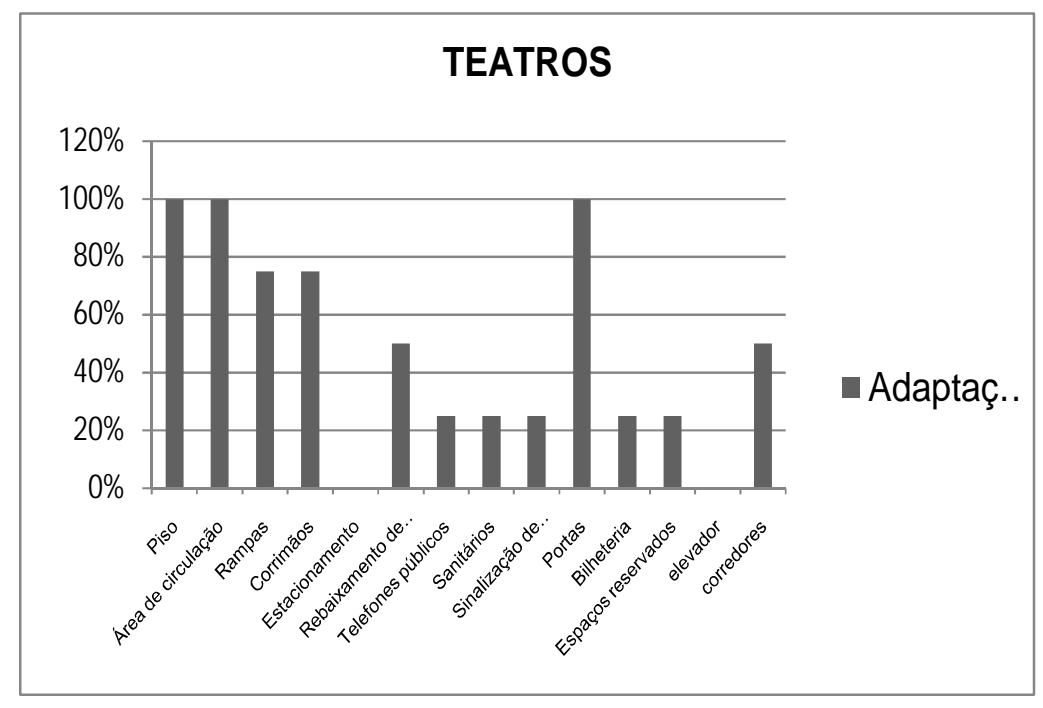

GRAFICO 3 - Avaliação das condições de acessibilidade dos teatros, Natal/2008.

O Decreto $n^{\circ} 5.296 / 2004$, que regulamenta a Lei $n^{\circ} 10.048 / 2000$, dispõe em seu art. 30 que:

As soluções destinadas à eliminação, redução ou superação de barreiras na promoção da acessibilidade a todos aos bens culturais imóveis devem estar de acordo com o que estabelece a Instrução Normativa $\mathrm{n}^{\mathrm{o}} 1$ do Instituto do Patrimônio Histórico e Artístico Nacional - IPHAN, de 25 de novembro de 2003.

Esta Instrução Normativa do IPHAN, que por força do contido na Lei 10.048/2000 (norma geral sobre acessibilidade) e no art. 30 do Decreto 5.296/2004, aplica-se também aos bens acautelados pelos Estados, Distrito Federal e Municípios $(\mathrm{CF} / 88$, art. 24, § 10.), estabelece diretrizes, critérios e recomendações para a promoção das devidas condições de acessibilidade aos bens culturais imóveis, a fim de equiparar as oportunidades de fruição destes bens pelo conjunto da sociedade, em especial pelas pessoas portadoras de deficiência ou com mobilidade reduzida. 
Francisco R. L. V. de Melo, Débora L. dos S.

Estudo da Acessibilidade em Ambientes de Lazer ...

Brandão, Laise C. de Oliveira, Larissa R. K. e Silva,

Lorenna M. de M. Santiago e Renata N. Delgado

Na avaliação dos cinemas GRAF. 4, a área de circulação, o piso, o elevador, a sinalização de degraus, os corrimãos, os sanitários, as portas, os corredores e as rampas mostravam-se com $100 \%$ de adaptação para as pessoas com deficiência física, já a bilheteria e os espaços reservados para pessoas com deficiência em teatros e cinemas apresentavam $50 \%$ de adaptação. Vale salientar que na avaliação dos cinemas não foi considerado o item estacionamento e telefones públicos, pois todos pertenciam a shoppings e não exclusivamente aos cinemas.

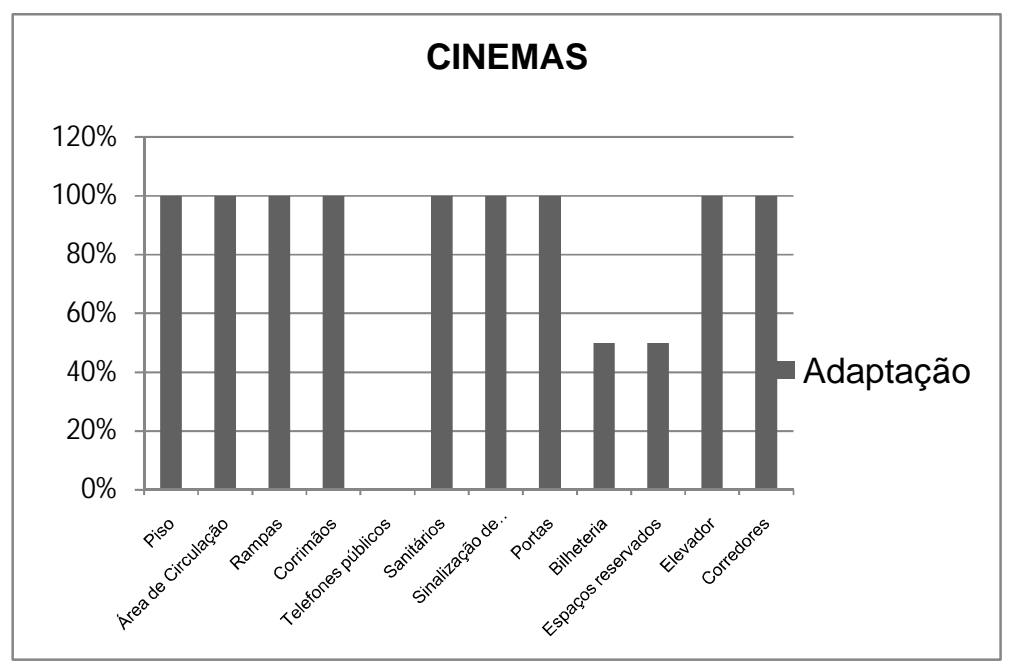

GRAFICO 4 - Avaliação das condições de acessibilidade dos cinemas, Natal/2008.

Um estudo feito com população adulta com deficiência física por Blascovi-Assis et al. (2005) relatou que as dificuldades financeiras, a falta de transporte e, principalmente, as instalações inadequadas figuravam entre as principais dificuldades apontadas pelo grupo entrevistado. O que pode ser comprovado por este estudo como mostra os resultados acima de acordo com as normas da ABNT. Contudo, os parques e 
Francisco R. L. V. de Melo, Débora L. dos S.

Estudo da Acessibilidade em Ambientes de Lazer ...

Brandão, Laise C. de Oliveira, Larissa R. K. e Silva,

Lorenna M. de M. Santiago e Renata N. Delgado

cinemas apresentaram melhor acessibilidade, embora não atendessem a todos os critérios.

Dentre as barreiras arquitetônicas normalmente encontradas, de acordo com Bisognin (1998) são: ausência de pisos adequados, degraus, rampas, dimensão de portas, corrimãos, banheiros e transporte urbano. Dentre esses, alguns itens avaliados são indispensáveis para um simples acesso ao ambiente de lazer como, por exemplo, rampas, pisos regulares e banheiros (RIBEIRO et al., 2007). No entanto, dentre os itens avaliados no presente estudo, os pisos analisados nos locais visitados mostravam-se adaptados, O mesmo ocorreu para as rampas analisadas, com exceção de algumas rampas nas praias da Redinha e Praia do Meio que se apresentaram fora das normas.

Juntamente com os banheiros, os telefones públicos obtiveram uma baixa porcentagem de adaptação. Estes estavam presentes, em adequadas condições, apenas no Teatro Alberto Maranhão e nos cinemas, de todos os locais visitados, com altura máxima de $0,73 \mathrm{~m}$ do piso.

A acessibilidade ao meio físico implica suprimir barreiras arquitetônicas e urbanísticas, como também de transporte, reconhecendo a inevitável necessidade de locomoção de todos os seres humanos. Para isso, já existem normas internacionais de conselhos de Arquitetura e Engenharia que lidam com a parte de adaptações em repartições e edificações em geral, que tornam os mesmos mais acessíveis às pessoas com deficiência (AGUIRRE ${ }^{4}, 2005$ apud ALMEIDA et al, 2005).

De acordo com as normas da ABNT, os elevadores deveriam apresentar instruções de uso, indicação de posição de embarque e indicação dos pavimentos atendidos; os corredores que tivessem até $4 \mathrm{~m}$, a largura deveria ser de no mínimo

\footnotetext{
${ }^{4}$ AGUIRRE, R. Recreação e Turismo para Todos. São Paulo: EDUCS, 2005.
} 
Francisco R. L. V. de Melo, Débora L. dos S.

Estudo da Acessibilidade em Ambientes de Lazer ...

Brandão, Laise C. de Oliveira, Larissa R. K. e Silva,

Lorenna M. de M. Santiago e Renata N. Delgado

0,90m, caso tivesse até $10 \mathrm{~m}$, a largura correspondente deveria ser no mínimo $1,20 \mathrm{~m}$ e sendo acima de $10 \mathrm{~m}$, a largura é de no mínimo 1,50m; os estacionamentos deveriam apresentar sinalização horizontal e vertical; os rebaixamentos de calçada para travessia de pedestre deveriam ter uma largura mínima de 0,80m; a área de circulação deveria ter no mínimo 1,20m de largura; já as bilheterias com uma altura máxima de 1,05m do piso e com local de encaixe para pernas no balcão e os espaços físicos em teatros e cinemas deveriam conter um número mínimo de espaços reservados para pessoas com cadeira de rodas $(\mathrm{ABNT}, 2004)$.

As portas analisadas estavam, no geral, dentro das normas, com um vão mínimo de $0,80 \mathrm{~m}$, nas quais também foram analisadas as maçanetas que deveriam ser do tipo alavanca, com altura entre 0,90m e 1,10m. Já os corrimãos só estavam bem adaptados instalados em ambos os lados dos degraus isolados, das escadas fixas e das rampas, com desenho continuo e altura de $0,70 \mathrm{~m}$ e $0,92 \mathrm{~m}$ - em todos os cinemas e em alguns teatros e parques. Os banheiros foram comprovados como sendo uma das principais barreiras arquitetônicas encontradas já que muitos dos sanitários não possuíam dimensões internas para girar $180^{\circ}(1,50 \mathrm{~m} \times 1,20 \mathrm{~m})$, barras com $0,75 \mathrm{~m}$ de altura do piso, bacia sanitária com $0,43 \mathrm{~m}$ a $0,45 \mathrm{~m}$ do piso e lavatório com borda superior entre $0,78 \mathrm{~m}$ e 0,80m e borda inferior, $0,73 \mathrm{~m}$ (ABNT, 2004).

Comparando os dados obtidos por essa pesquisa com uma análise semelhante realizada por Ribeiro et al (2007) na cidade de Salvador/BA, podemos observar que nas duas cidades os cinemas apresentavam portas, pisos e corredores adaptados, porém as bilheterias e os espaços reservados para cinema/teatros não estavam adequados, o que impede a participação de pessoas usuárias de cadeiras de rodas nesses serviços. Nos teatros, apenas as portas apresentavam-se adaptadas nas duas cidades; rampas, 
Francisco R. L. V. de Melo, Débora L. dos S.

Estudo da Acessibilidade em Ambientes de Lazer ...

Brandão, Laise C. de Oliveira, Larissa R. K. e Silva,

Lorenna M. de M. Santiago e Renata N. Delgado

corrimãos, rebaixamento de calçadas, telefones públicos, bilheterias, elevadores, sanitários, espaços reservados em teatros e cinemas e sinalização de degraus estavam em ambas as cidades não adaptados, assim como, telefones públicos, sanitários, portas e corrimãos nos parques.

A falta de acessibilidade a determinados locais e serviços leva as pessoas com deficiência a se sentirem a margem da sociedade, gerando, muitas vezes, perturbações de estima e comportamento, o que contribui ainda mais para a segregação social (ROCHA ${ }^{5}, 2001$ apud RIBEIRO et al., 2007). Uma das razões para a falta de acesso aos locais de lazer pode ser justificada de acordo com o estudo de Peres e Melo (2006), o qual sugere que as secretarias de esporte, lazer e cultura são contempladas com a menor fração do orçamento nas negociações políticas, estando o governo, sempre mais preocupado com superávits, balanços positivos e ajustes fiscais do que com outras dimensões também fundamentais para o bem estar humano.

Faz-se necessário que a consciência social a respeito da deficiência se propague na sociedade. A resolução do problema virá essencialmente das ações coletivas promovidas pelas várias frentes da mesma. Somente a clareza sobre a problemática pode fomentar e viabilizar os recursos necessários para propor soluções eficazes. Porém, será muito relevante a participação dos organismos públicos com vontade política para a difusão massiva do problema, a busca pela conscientização popular seria

\footnotetext{
${ }^{5}$ ROCHA, V. M. et al. Lazer e atenção multidisciplinar no desenvolvimento de pessoas com necessidades especiais. In: COLÓQUIO INTERNACIONAL DA AFIRSE X COLÓQUIO NACIONAL DA AFIRSE I - Secção Brasileira, 2001, Natal. Comunicações Científicas. Natal: AFIRSE/UFRN, 2001.
} 
Francisco R. L. V. de Melo, Débora L. dos S.

Estudo da Acessibilidade em Ambientes de Lazer ...

Brandão, Laise C. de Oliveira, Larissa R. K. e Silva,

Lorenna M. de M. Santiago e Renata N. Delgado

um primeiro grande passo para a inclusão social das pessoas com necessidade especiais (AGUIRRE ${ }^{6}, 2005$ apud ALMEIDA et al, 2005).

Ver filmes, assistir a partidas de futebol, ouvir rádio e outras formas de lazer são, para Russell ${ }^{7}$, (2002 apud SANTOS et al., 2008) prazeres das populações urbanas, que se tornaram essencialmente passivas. Este fenômeno ocorre pela falta de lazer fora de casa e pelo excesso de trabalho que absorve as energias da população proporcionando, assim, mais lazer às pessoas com deficiência ou então elas não participariam e desfrutariam mais ativamente dos prazeres. Em contrapartida, o estudo de Peres e Melo (2006) mostra uma privatização das vivências cotidianas, onde se pode observar que as pessoas estão cada vez mais limitadas a seu espaço doméstico, utilizando os equipamentos tecnológicos (televisão, vídeo, DVD, internet) como mediadores de sua interação com a realidade, o que acaba por reduzir sensivelmente as expressões humanas e afetivas.

A postura crítica de Milton Santos ${ }^{8}$, (2002 apud SANTOS et al., 2008) em relação aos jornais, rádios, televisão, enfim, à imprensa, entende que através da tirania da mídia, a informação passa a ser ministrada como propaganda, manipulando imagens do mundo e das pessoas. Além disso, em nosso entendimento, apenas estas formas de lazer não proporcionam a integração com a sociedade e dificulta a cobrança por medidas a favor da inclusão.

A carência de acessibilidade e de políticas públicas foram aspectos identificados nos espaços de lazer da cidade do Natal, corroborando com os achados de Maia e Almeida (2008), que além desses aspectos, identificaram a falta de

\footnotetext{
${ }^{6}$ AGUIRRE, R. Recreação e Turismo para Todos. São Paulo: EDUCS, 2005.

${ }^{7}$ RUSSELL, Bertrand . O elogio ao ócio. Rio de Janeiro: Sextante, 2002.

${ }^{8}$ SANTOS, Milton. A natureza do espaço: técnica e tempo - razão e emoção. São Paulo: Edusp, 2002. $384 \mathrm{p}$.
} 
Francisco R. L. V. de Melo, Débora L. dos S.

Estudo da Acessibilidade em Ambientes de Lazer ...

Brandão, Laise C. de Oliveira, Larissa R. K. e Silva,

Lorenna M. de M. Santiago e Renata N. Delgado

conhecimento a respeito de questões relacionadas a estas pessoas e o superprotecionismo por parte da família e dos que cercam esses indivíduos. Apesar de o lazer ser um direito assegurado a todo cidadão, muitas pessoas, inclusive aquelas com deficiência, não desfrutam do mesmo.

\section{CONSIDERAÇÕES FINAIS}

Estudar as possibilidades de lazer, nas condições em que vive a maioria das pessoas com deficiência hoje, representa a reflexão sobre o direito fundamental da pessoa enquanto cidadão. Lutar pela "democratização do lazer" significa optar por um caminho diferente na conquista de melhores condições de vida em sociedade. Dessa forma, pode-se concluir que os ambientes de lazer que foram foco deste estudo na cidade do Natal/RN, apesar de se mostrarem com vários pontos de inadequação, apresentam possibilidades de melhora na maioria dos itens avaliados com relação à ABNT, norma NBR 9050/94.

É fundamental novos estudos sobre essa temática buscando denunciar o descompromisso das autoridades e das políticas publicas em relação a essa questão como forma de pressionar a garantia desse direito, assim como mostrem outros parâmetros ergonômicos e de acessibilidade com o objetivo de oportunizar o ganho na qualidade de lazer, perseverando na contribuição para a melhoria de vida dos indivíduos com deficiência, principalmente física ou mobilidade reduzida.

Nesse sentido, esperamos que as políticas públicas no Brasil se voltem para ações de forma intensa e continuada nas quais as pessoas com deficiência possam de fato estar incluídas em todos os espaços sociais, inclusive de lazer, no âmbito da comunidade a que pertençam, proporcionando diversão e qualidade de vida. 


\section{REFERÊNCIAS}

ALMEIDA, R. A. et.al. Lazer e turismo. Resolução de problemas II. Relatório Científico III. Roteiros Turísticos para Pessoas com Necessidades Especiais. Turismo Adaptado. Universidade de São Paulo. São Paulo, 2005.

ASSOCIAÇÃO BRASILEIRA DE NORMAS TÉCNICAS. NBR 9050: Acessibilidade a edificações, mobiliário, espaços e equipamentos urbanos. 2. ed. Rio de Janeiro, 2004.

ASSOCIAÇÃO MUNDIAL DE RECREAÇÃO E LAZER. SEMINÁRIO INTERNACIONAL DA WLRA DE EDUCAÇÃO PARA O LAZER EM JERUSALÉM - Israel, de 2 a 4 de agosto de 1993. Carta internacional de educação para o lazer. Brasília: SESI - DN, 1995.

BISOGNIN, E. M. Barreiras sócio-culturais e lazer das pessoas portadoras de deficiência física: um estudo do grupo Fraternidade Cristã de Doença e Deficiência de Campinas. Dissertação (Mestrado em Educação Física) - Programa de Pós-Graduação em Educação Física, UNICAMP ,Campinas, SP, 1998.

BLASCOVI-ASSIS et al. Lazer familiar: um estudo sobre a percepção de pais de crianças com deficiência. Cadernos de Pós-Graduação em Distúrbios do Desenvolvimento (PG-Distúrbios), Universidade Presbiteriana Mackenzie, v. 5, n. 01, 2005. Disponível em: <http://www4.mackenzie.br/ fileadmin/Pos_Graduacao/ Mestrado/Disturbios_do_Desenvolvimento/Publicacoes/volume_V/lazer_familiar.pdf >. Acesso em: 13 jun. 2008.

BRASIL. Lei n. 7.853 de 24 de outubro de 1989. Diário Oficial da União, Brasília, DF, 25 out. 1989.

. Decreto $\mathrm{n}^{\text {o. }} 5.296$ de 2 de dezembro de 2004. Diário Oficial da União. Regulamenta as Leis nos 10.048 , de 8 de novembro de 2000, que as soluções destinadas à eliminação, redução ou superação de barreiras na promoção da acessibilidade a todos aos bens culturais imóveis devem estar de acordo com o que estabelece a Instrução Normativa $\mathrm{n}^{\circ} 1$ do Instituto do Patrimônio Histórico e Artístico Nacional - IPHAN, de 25 de novembro de 2003.Disponível em: <http://www.planalto.gov.br/ccivil_03/_Ato2004-2006/2004/Decreto/D5296.htm>. Acesso em: 05 dez. 2009.

DECLARAÇÃO DE SALAMANCA: Sobre Princípios, Políticas e Práticas na Área das Necessidades Educativas. Conferência Mundial de Educação Especial. Salamanca, Espanha. $\quad 7$ e 10 jun. 1994. Disponível em: <http://portal.mec.gov.br/seesp/arquivos/pdf/salamanca.pdf>. Acesso em: 10 maio 09.

INSTITUTO BRASILEIRO DE GEOGRAFIA E ESTATÍSTICA. Disponível em: <http://www.IBGE.gov.br>. Acesso em: 21 maio 2008. 
MAIA, D. M.; ALMEIDA, A. C. P. Políticas públicas e o lazer voltado para a inclusão da pessoa com necessidades especiais em Salvador. In: SEMINÁRIO DE EDUCAÇÃO FÍSICA DA UNIVERSIDADE DO ESTADO DA BAHIA, 10., 2008, Anais... Alagoinhas: DEDC/UNEB, 2008.

MARCELLINO, Nelson Carvalho. O entendimento do lazer. In: Políticas públicas setoriais de lazer: o papel das prefeituras. Campinas: Autores Associados, 1996. p. 01-06.

MESSA, Alcione Aparecida et al. Lazer familiar: um estudo sobre a percepção de pais de crianças com deficiência. 2005. Dissertação (Mestrado em Distúrbios do Desenvolvimento) - Universidade Presbiteriana Mackenzie, São Paulo, 2005.

PELLEGRIN, Ana De. O espaço de lazer na cidade e a administração municipal. In: MARCELliNO, Nelson Carvalho. Políticas públicas setoriais de lazer: o papel das prefeituras. Campinas: Autores Associados, 1996. p. 31-38.

PERES, F. F.; MELO, V. A. Espaço, lazer e política: desigualdades na distribuição de equipamentos culturais na cidade do Rio de Janeiro. Lecturas: EF y Deportes. Revista Digital. Buenos Aires, Ano 10, n. 93, fev. de 2006. Disponível em: <http://www.efdeportes.com/efd93/rio.htm>. Acesso em: 16 maio 2009.

RIBEIRO, N. M. S. et al. Análise do ambiente de lazer para portadores de deficiência física com alteração na locomoção, na cidade de Salvador. Revista Diálogos Possíveis, jan./jun., p. 233-242, 2007.

SANTOS, A. et al. Lazer, esporte, jogo e trabalho uma relação com a deficiência. Revista Diálogos Possíveis, Ano 5, n. 01, jan./jun. p. 173-187, 2006,. Disponível em: $<$ http://www.fsba.edu.br/dialogospossiveis /artigos/8/12.pdf >. Acesso em: 13 jun. 2008.

\section{Endereço dos autores:}

Francisco Ricardo Lins Vieira de Melo

End.: Avenida Ayrton Sena, 880

Condomínio Bosque das Palmeiras, casa 160. Nova Parnamirim.

Parnamirim/RN CEP: 59151-600

Endereço eletrônico: ricardolins@ @ufrnet.br

Débora Luciana dos Santos Brandão

End.: Avenida Gandhi, 1600, casa 19

condomínio Mahatma Gandhi. Nova Parnamirim.

Parnamirim/RN CEP: 59152-780

Endereço eletrônico: debora.luciana@gmail.com 
Francisco R. L. V. de Melo, Débora L. dos S.

Brandão, Laise C. de Oliveira, Larissa R. K. e Silva,

Lorenna M. de M. Santiago e Renata N. Delgado

Laise Chaves de Oliveira

End.: Rua Alberto Silva, 1361, Bloco G, Apart. 304

Edifício Vila Romana 3. Bairro Lagoa Seca.

Natal/RN CEP: 59022-300

Endereço eletrônico: lchavesoliveira@yahoo.com.br

Larissa Raquel Klemig e Silva

End.: Rua Anfilóquio Paiva Câmara, 27

Lagoa Nova. Natal/RN CEP: 59075-030

Endereço eletrônico: lalaquell@yahoo.com.br

Lorenna Marques de Melo Santiago

End.: Rua Praia de Muriú, 202. Nova Parnamirim.

Parnamirim/RN CEP: 59151-427

Endereço eletrônico: lorenna.santiago@yahoo.com.br

Renata Nóbrega Delgado

End.: Rua Dom Joaquim de Almeida, 276

Bloco D, Apart. 504, Condomínio Parque das Serras.

Bairro Morro Branco. Natal/RN CEP: 59056-140

Endereço eletrônico: natinha_ndelgado@ hotmail.com 